УДК 621.396

Олександр Юрійович Пермяков (доктор технічних наук, професор)

Юрій Борисович Прібилєв (кандидт технічних наук, доцент) Андрій Олександрович Дядечко

Національний університет оборони Украӥни імені Івана Черняховського, Київ, Украӥна

\title{
ОЦІНКА ПОТОКІВ ВИМІРЮВАЛЬНОЇ ІНФОРМАЦІї КОНТРОЛЬНО-ВИПРОБУВАЛЬНОЇ СТАНЦІЇ
}

У статті проведена очінка потоків інформації КВС на основі відомих положень теорії зв'язку у залежності від способу обробки проміжних результатів контролю. Детально розглянути закономірності утворення потоків відліків у пристроях з цииклічним послідовним опитуванням датчиків $i$ принципові можливості покращення характеристик КВС за рахунок введення підсистеми попередньої обробки інформачії. Визначений вплив параметрів КВС, обсягу задач контролю та дальності передачі інформації на конструктивні характеристики КВС (масу, вартість КВС). Оиінювання інформаційних потоків у КВС дозволило зв'язати параметри КВС (кількість датчиків, точність вимірювання, потік відліків і алгоритм дискретизації функиій) з параметрами пристрою передачі інформації (пропускної здатності каналу зв'язку, відношенням сигнал/шум). Отримані відношення можуть бути використані при проектуванні КВС та ї̈ оптимізації за вартісним критерієм.

Ключові слова: контрольно-випробувальна станція, інформація, датчик.

\section{Вступ}

Основним джерелом інформації про готовність зенітних ракетних комплексів (ЗРК) $є$ проведення регламентних та контрольно-випробувальних робіт з зенітними керованими ракетами (ЗКР) за допомогою контрольно-випробувальних станцій (КВС). Розробка нових ракетних комплексів супроводжується зростанням їх складності та технологічного рівня, що вимагає підвищення ефективності контролю та розробки КВС 3 використанням сучасних інформаційних технологій. Тому дослідження щодо застосування інформаційних технологій при визначенні підходів до проектування КВС є актуальними $[1,2]$.

Постановка проблеми. При побудові КВС виробники вирішують завдання забезпечення мінімальних витрат при заданому значенні ефективності контролю технічного стану ЗКР при визначених обмеженнях. Для рішення цього завдання актуальною $\epsilon$ розробка теоретичних положень оцінки потоків вимірювальної інформації КВС, що дозволить здійснити проектування КВС за мінімумом витрат.

Аналіз останніх досліджень і публікацій. ЗКР $\epsilon$ складною технічною системою, яка характеризується різноманітними показниками, які необхідно контролювати під час експлуатації [3]. Розробкою методів технічної експлуатації ЗКР і підтримання технічної готовності ЗРК займались автори [4, 5]. У роботі [2] наведені загальні вимоги до КВС, але потоки вимірювальної інформації КВС, ще не досліджені.

Метою статті $є$ оцінка потоків вимірювальної інформації КВС.

\section{Виклад основного матеріалу дослідження}

КВС $\epsilon$ інформаційною системою, яка для розрахунків пропускної здатності каналів зв'язку і пристроїв обробки інформації потребує проведення оцінки потоків інформації, що циркулюють у КВС.

Метод оцінки потоків інформації у КВС залежить від способу обробки проміжних результатів контролю. Залежно від того, як оцінюється значення кожного контрольованого параметру, способи обробки підрозділяються на допускові і кількісні.

Допускові системи контролю здійснюють оцінку параметрів двома способами:

1) шляхом фіксування виходу параметра за межі, що визначаються значеннями $Y_{H}, Y_{B}$. Такі системи називаються допусковими системами контролю типу “так - ні";

2) шляхом оцінки знаку відхилення параметру при виході його за допустимі межі. Такі системи називаються допусковими системами контролю типу “менше - норма - більше".

Основною характеристикою каналу зв'язку $є$ його пропускна здатність $\mathrm{R}=\frac{\mathrm{i}_{\max }}{\mathrm{t}}$, що визначає найбільшу кількість інформації, що може бути передана каналом зв'язку в одиницю часу.

Максимальна кількість вторинної інформації (тобто інформації, що знімається з датчиків КВС) у двійкових одиницях визначається за формулою:

$$
\mathrm{J}=\mathrm{k}_{\mathrm{d}}+\sum_{\mathrm{i}=1}^{\mathrm{k}-\mathrm{k}_{\mathrm{d}}} \frac{1}{\delta_{\mathrm{i}}},
$$

де $\mathrm{k}_{\mathrm{d}}$ - кількість контрольованих параметрів 3 допусковою системою оцінки.

$\delta_{\mathrm{i}}-$ середня квадратична помилка датчика.

(C) О.Ю. Пермяков, Ю.Б. Прібилєв, А.О. Дядечко

Modern Information Technologies in the Sphere of Security and Defence $\mathcal{N} N$ 1(34)/2019 ISSS2311-7249(Print)/ISSN2410-7336(Onfine) 
3 урахуванням цієї формули потік інформації не перевищує величини:

$$
\Lambda=\frac{\mathrm{k}_{\mathrm{d}}+\sum_{\mathrm{i}=1}^{\mathrm{k}_{\mathrm{k}}} \frac{1}{\xi_{\mathrm{i}}}}{\Delta \mathrm{t}_{\text {min }}},
$$

де $\mathrm{k}_{\mathrm{d}}$ - кількість контрольованих параметрів 3 кількісною оцінкою;

$\mathrm{k}_{\mathrm{k}}$ - кількість контрольованих параметрів 3 допусковою оцінкою;

$\xi$ - клас точності вимірювального каналу, що вимірює і-тий параметр;

$\Delta \mathrm{t}_{\min }$ - час зняття одного відліку з датчика, який має максимальну швидкодію.

Така оцінка інформаційних потоків пред'являє дещо завищені вимоги до каналів зв'язку i пристроїв обробки, але залишає можливість коригування і є вихідною передумовою при виборі способу обробки інформації. Серед пристроїв збору інформації найбільше поширення через простоту отримали пристрої 3 циклічним послідовним опитуванням джерел вимірювальної інформації - датчиків.

Розглянемо детальніше закономірності утворення ними потоків відліків i принципові можливості отримання різних технічних ефектів за рахунок введення підсистеми попередньої обробки інформації. У циклічній системі формування потоку відліків та їх вимірювання здійснюються у момент комутації датчика.

Нехай сукупність джерел інформації складається 3 D датчиків, стан яких $\mathrm{X}_{1}, \mathrm{X}_{2}, \ldots$, $\mathrm{X}_{\mathrm{D}}$ характеризується ентропіями $\mathrm{H}\left(\mathrm{X}_{1}\right), \mathrm{H}\left(\mathrm{X}_{2}\right)$, $\ldots, \mathrm{H}\left(\mathrm{X}_{\mathrm{D}}\right)$. Ентропію можна розглядати як кількість інформації, яка приходиться на один елемент повідомлення, а у випадку розгляду циклічної системи (при послідовному у часі опитуванні датчиків) - як кількість інформації на одне опитування. Загальна ентропія комплексного датчика дорівнює ентропії всіх повідомлень:

$$
\mathrm{H}(\mathrm{X})=\mathrm{H}\left(\mathrm{X}_{1}, \mathrm{X}_{2}, \ldots, \mathrm{X}_{\mathrm{D}}\right) \text {, }
$$

Якщо повідомлення окремих датчиків статистично незалежні, то загальна ентропія дорівнює сумі ентропій:

$$
\mathrm{H}(\mathrm{X})=\mathrm{H}\left(\mathrm{X}_{1}\right)+\mathrm{H}\left(\mathrm{X}_{2}\right)+\ldots+\mathrm{H}\left(\mathrm{X}_{\mathrm{D}}\right),
$$

тобто $\mathrm{H}(\mathrm{X})$ можна розглядати як оцінку зверху найбільшої кількості інформації, яку видає комплексний датчик.

Ентропія повідомлень окремих датчиків дорівнює:

$$
\mathrm{H}\left(\mathrm{X}_{\mathrm{i}}\right)=-\sum_{\mathrm{k}=1}^{\mathrm{m}_{\mathrm{i}}} \mathrm{P}_{\mathrm{i}}\left(\mathrm{X}_{\mathrm{k}}\right) \log \mathrm{P}_{\mathrm{i}}\left(\mathrm{X}_{\mathrm{k}}\right),
$$

де i - порядковий номер і-го датчика;

$\mathrm{m}_{\mathrm{i}}$ - кількість станів і-го датчика;

$\mathrm{P}_{\mathrm{i}}\left(\mathrm{X}_{\mathrm{k}}\right)$ - ймовірність появи k-го стану i-го датчика.

Вважаючи рівноймовірними стани датчиків (оцінка зверху), маємо:

$$
\mathrm{H}(\mathrm{X})=\log \mathrm{m}_{1}+\log \mathrm{m}_{2}+\ldots+\log \mathrm{m}_{\mathrm{D}},
$$

Похибки датчиків

визначимо співвідношеннями:

$$
\delta_{1}=\frac{100}{\mathrm{~m}_{1}} ; \quad \delta_{2}=\frac{100}{\mathrm{~m}_{2}} ; \quad \delta_{\mathrm{D}}=\frac{100}{\mathrm{~m}_{\mathrm{D}}} ，
$$

Еквівалентна точність комплексного датчика дорівнює:

$$
\delta_{\mathrm{e}}=\sqrt[Д]{\delta_{1} \delta_{2} \ldots \delta_{\mathrm{D}}},
$$

Ентропія комплексного датчика дорівнює:

$$
\mathrm{H}(\mathrm{X})=Д \log \frac{100}{\delta_{\mathrm{e}}},
$$

Відповідно до теореми Котельникова для відтворення безперервної функції $\varphi(\mathrm{t})$ за допомогою послідовності дискретних відліків необхідно ці відліки взяти через інтервали часу, що визначаються співвідношенням:

$$
\Delta \mathrm{t}_{\min }=\frac{1}{2 \mathrm{f}_{\mathrm{D}_{\max }}},
$$

де $\mathrm{f}_{\mathrm{D}_{\max }}$ - максимальна частота, яка обмежує спектр частот переданої функції.

Кількість опитувань в одиницю часу для комплексного датчика:

$$
\mathrm{F}_{0}=\frac{1}{\Delta \mathrm{t}_{\min }}=2 \mathrm{f}_{\mathrm{D}_{\max }} .
$$

Швидкість видачі інформації (у біт/с) комплексним датчиком дорівнює:

$$
\mathrm{F}_{0} \mathrm{H}(\mathrm{X})=\mathrm{F}_{0} \mathrm{D} \log \frac{100}{\delta_{\mathrm{e}}} .
$$

Потік відліків, які знімаються 3 датчиків, буде рівномірним з інтенсивністю:

$$
\Lambda\left(\Gamma_{0}\right)=\mathrm{DF}_{0},
$$

тобто дорівнюе сумарній ширині смуги інформації, яка передається. Через $\Gamma_{0}$ позначений найпростіший алгоритм визначення істотних відліків, тобто це алгоритм рівномірної циклічної вибірки, відповідно до якого на передачу надходять всі відліки рівномірної дискретизації функції. Схема передачі інформації від деякого джерела у цьому випадку має пристрій збору інформації, пристрій обробки інформації та джерело завад.

Кількість інформації, яка містіться у прийнятих повідомленнях $\mathrm{Y}$ відносно переданих $\mathrm{X}$ (за умови, що $\mathrm{X}$ незалежне від $\mathrm{N}$ ):

$$
\mathrm{I}(\mathrm{Y}, \mathrm{X})=\mathrm{H}(\mathrm{Y})-\mathrm{H}(\mathrm{N}) \text {. }
$$

Якщо час передачі інформації - T, то швидкість передачі інформації через канал зв'язку з завадами дорівнює:

$$
\mathrm{R}=\lim _{\mathrm{T} \rightarrow \infty} \frac{\mathrm{I}(\mathrm{Y}, \mathrm{X})}{\mathrm{T}}=\lim _{\mathrm{T} \rightarrow \infty} \frac{\mathrm{H}(\mathrm{Y})-\mathrm{H}(\mathrm{N})}{\mathrm{T}} .
$$

Найбільша швидкість передачі інформації називається пропускною спроможністю каналу зв'язку із завадами, причому:

$$
\mathrm{R}_{\max }=\lim _{\mathrm{T} \rightarrow \infty} \frac{\mathrm{I}_{\max }(\mathrm{Y}, \mathrm{X})}{\mathrm{T}} .
$$

Найбільша кількість інформації, що міститься у прийнятому повідомленні У відносно переданого повідомлення $\mathrm{X}$ : 


$$
\mathrm{I}_{\max }(\mathrm{Y}, \mathrm{X})=2 \mathrm{~F}_{0} \mathrm{~T} \log \frac{\sigma_{\mathrm{y}}}{\sigma_{\mathrm{n}}},
$$

де $\sigma_{\mathrm{y}}$ i $\sigma_{\mathrm{n}}$ - відповідно середні квадрати прийнятого повідомлення і завади.

Оскільки $\sigma_{\mathrm{y}}^{2}=\sigma_{\mathrm{X}}^{2}+\sigma_{\mathrm{n}}^{2}$, зробимо заміну:

$$
\frac{\sigma_{X}^{2}}{\sigma_{n}^{2}}=\frac{P}{N},
$$

де $\mathrm{P}$ - середнє значення потужності переданих повідомлень, а $\mathrm{N}$ - середнє значення потужності завад.

Отримаємо:

$$
\mathrm{I}_{\max }(\mathrm{Y}, \mathrm{X})=\mathrm{FT} \log \left(1+\frac{\mathrm{P}}{\mathrm{N}}\right)
$$

де F - ширина спектру сигналу i завади (або ширина смуги каналу зв'язку).

Тоді:

$$
\mathrm{R}_{\text {max }}=\lim _{\mathrm{T} \rightarrow \infty} \frac{\mathrm{I}_{\max }(\mathrm{Y}, \mathrm{X})}{\mathrm{T}}=\mathrm{F} \log \left(1+\frac{\mathrm{P}}{\mathrm{N}}\right),
$$

тобто швидкість передачі інформації пропорційна ширині смуги частот комплексного датчика (джерела інформації), і логарифму суми $\left(1+\frac{\mathrm{P}}{\mathrm{N}}\right)$.

Ці положення теорії зв'язку дозволяють зв'язати параметри КВС (кількість датчиків, точність вимірювання, потік відліків і обраний алгоритм дискретизації функцій) 3 параметрами пристрою передачі інформації (пропускною здатністю каналу зв'язку, відношенням сигнал/шум). Отримані відношення можуть бути корисними при визначенні підходів і рішень задач проектування КВС, а також оптимізації іï побудови за критеріями мінімуму конструктивних ресурсів (маси, вартості і т. і.).

У циклічних пристроях збору інформації узгодження потоку повідомлень комплексного датчика 3 пропускною здатністю каналу передачі даних досягається шляхом вибору максимальної пропускної здатності каналу зв'язку згідно нерівності:

$$
\mathrm{F}_{0} \mathrm{D} \log \frac{100}{\delta_{\mathrm{e}}} \leq \mathrm{R}_{\text {max }}=\mathrm{F}_{0} \log \left(1+\frac{\mathrm{P}}{\mathrm{N}}\right) .
$$

Звідси знаходимо умову для визначення найменшої ширини смуги пропускання каналу передачі даних:

$$
\mathrm{F}_{0} \geq \mathrm{f}_{0} \mathrm{D} \frac{\log \frac{100}{\delta_{\mathrm{e}}}}{\log \left(1+\frac{\mathrm{P}}{\mathrm{N}}\right)}=\Lambda_{0}\left(\Gamma_{0}\right) \frac{\mathrm{A}\left(\delta_{\mathrm{e}}\right)}{\mathrm{B}\left(\frac{\mathrm{P}}{\mathrm{N}}\right)},
$$

тобто ширина смуги каналу передачі даних для циклічного алгоритму формування повідомлень повинна бути тим більшою, чим вище швидкість опитування джерел інформації $\mathrm{f}_{0}$, чим більша їх кількість D, вища точність $\delta_{\mathrm{e}} \mathrm{i}$ чим менше відношення сигнал/шум у приймальному пристрої.

Запишемо вираз (22) у наступному вигляді:

$$
\mathrm{F}_{0} \geq \frac{\Lambda\left(\Gamma_{0}\right)}{\Lambda(\Lambda)} \Lambda(\Gamma) \frac{\mathrm{A}\left(\delta_{\mathrm{e}}\right)}{\mathrm{B}\left(\frac{\mathrm{P}}{\mathrm{N}}\right)}=\mathrm{k}_{\mathrm{cr}}(\Gamma) \Lambda(\Gamma) \frac{\mathrm{A}\left(\delta_{\mathrm{e}}\right)}{\mathrm{B}\left(\frac{\mathrm{P}}{\mathrm{N}}\right)}
$$

де $\mathrm{k}_{\mathrm{c \tau}}(\Gamma)=\frac{\Lambda\left(\Gamma_{0}\right)}{\Lambda(\Lambda)}-$ коефіцієнт

стискання

інформації, рівний відношенню сумарних інтенсивностей потоків повідомлень, що отримані при використанні рівномірного циклічного $\Gamma_{0}$ та деякого (що дає меншу інтенсивність потоку відліків) алгоритму дискретизації. Коефіцієнт стискання інформації $\mathrm{k}_{\mathrm{cт}}$ може змінюватися від 1 до $\mathrm{k}_{\mathrm{cT}_{\max }}(\Gamma)$.

Визначимо вплив параметрів КВС, обсягу задач контролю та дальності передачі інформації на конструктивні характеристики (масу, вартість) KBC.

1. При заданих еквівалентній точності джерел інформації $\delta_{\mathrm{e}}$ i умовах прийому $\left(\mathrm{B}\left(\frac{\mathrm{P}}{\mathrm{N}}\right)\right.$ ), зростання кількості джерел інформації D веде до зростання сумарної ширини смуги каналу передачі даних.

2. Скорочення переданого потоку повідомлень

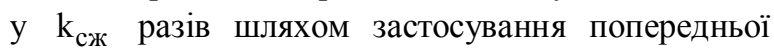
обробки рівномірного циклічного потоку відліків за алгоритмами стиснення призводить до звуження смуги у стільки ж разів, а отже, і до зниження витрат на передачу інформації.

3. При фіксованій смузі передачі інформації резерв інформативності $\Delta \Lambda(\Gamma)=\Lambda\left(\Gamma_{0}\right)-\Lambda(\Gamma)$ (що виникає за рахунок стиснення первинного циклічного потоку повідомлень), можна обміняти на:

а) збільшення кількості джерел інформації D, що одночасно обслуговуються;

б) збільшення точності передачі сигналів датчиків за рахунок збільшення частоти їх опитування;

в) зменшення допустимого відношення $\frac{\mathrm{P}}{\mathrm{N}}$ :

- за рахунок зменшення енергетики бортового передавача інформації;

- за рахунок збільшення дальності зв'язку.

Мінімізація потоку інформації $\epsilon$ потужним фактором оптимізації характеристик ЗРК i повинна обов'язково проводитися при побудові KBC.

\section{Висновки й перспективи подальших досліджень}

Таким чином, у статті проведена оцінка інформаційних потоків на основі відомих положень теорії зв'язку, що дозволило зв'язати параметри КВС (кількість датчиків, точність вимірювання, потік відліків і алгоритм дискретизації функцій) 3 параметрами пристрою передачі інформації (пропускної здатністю каналу зв'язку та відношенням сигнал/шум). Отримані відношення можуть бути використаними при проектуванні КВС та іiі оптимізації КВС за вартісним критерієм. 


\section{Лumepamypa}

1. Карпенко Д.В. Стан та перспективи розвитку зенітного ракетного озброєння Повітряних Сил Збройних Сил України: Науковий журнал "Наука i техніка Повітряних Сил Збройних Сил України”. 2017. № 2(27). С.75-78. 2. Прібилєв Ю.Б. Підхід до побудови уніфікованої універсальної автоматизованої контрольновипробувальної станції ракетного озброєння. / Ю. Б. Прібилєв， Л. В Сакович. // Наука і оборона. 2017. - № 1. - С. 42-48. 3. . Архангельский И. И. Проектирование зенитных управляемых ракет. / И. И. Архангельский П. П. Афанасьев, И. С. Голубев,
В. Г. Светлов и др. - М.: МАИ, 2001. - 732 с. 4. Гриб Д. А. Удосконалення методів технічної експлуатації i ремонту як основа підтримання боєготового стану зенітного ракетного озброєння в сучасних умовах [Текст] / Д. А. Гриб, Б. М. Ланецький, В. В. Лук'янчук // Наука і оборона. - 2012. - №3. - С. 55-63. 5. Пермяков О. Ю. Модель системи діагностування, технічного обслуговування та ремонту складних технічних систем військового призначення. / О. Ю. Пермяков, Ю. Б. Прібилєв, О. О. Дюбанов. // Наука і оборона. - 2016. - № 2. - С. 48-52.

\title{
ОЦЕНКА ПОТОКОВ ИЗМЕРИТЕЛЬНОЙ ИНФОРМАЦИИ КОНТРОЛЬНО-ИСПЫТАТЕЛЬНОЙ СТАНЦИИ
}

\author{
Александр Юрьевич Пермяков (доктор технических наук, профессор) \\ Юрий Борисович Прибылев (кандидат технических наук, доцент) \\ Андрей Александрович Дядечко
}

\section{Национальный университет обороны Украины имени Ивана Черняховского, Киев, Украина}

В статье проведена оценка потоков информации КИС на основе известных положений теории связи в зависимости от способа обработки промежуточных результатов контроля. Подробно рассмотрень закономерности образования потоков отсчетов в устройствах с ичиклиеским последовательным опросом датчиков и принципиальные возможности улучшения характеристик КИС за счет введения подсистемы предварительной обработки информации. Определено влияние параметров КИС, объема задач контроля и дальности передачи информации на конструктивные характеристики (массу, стоимость) КИС. Оиенка информаџионных потоков в КИС позволила связать параметры КИС (количество датчиков, точность измерения, поток отсчетов и алгоритм дискретизации функций) с параметрами устройства передачи информации (пропускной способностью канала связи, отнотением сигнал/шум). Полученные соотношения могут быть использованы при проектировании КИС и ее оптимизации по стоимостному критерию.

Ключевые слова: контрольно-испытательная станция, информация, датчик.

\section{ESTIMATION OF INFORMATION FLOWS OF THE CONTROL AND TEST STATION}

\author{
Oleksandr Permiakov (Doctor of technical sciences, Professor) \\ Yurii Pribyliev (Candidate of Technical Sciences, Associate Professor) \\ Andrii Dyadechko
}

\section{National Defence University of Ukraine named after Ivan Cherniakhovsky, Kyiv, Ukraine}

There is carried out the estimation of information flows of the test station on the basis of the known positions of the theory of communication depending on the method of processing of intermediate results of control. There we also considered the patterns of formation of reference currents in devices with cyclic sequential sensor survey and the principal possibilities of improving the characteristics of the test station by introducing a subsystem of pre-processing information. The influence of the parameters of the test station, the scope of control tasks and the range of information transmission on the constructive characteristics of the test station (weight, cost of test station) is determined. The estimation of information flows in the test station has made it possible to link the parameters of the test station (number of sensors, measurement accuracy, reference flow and sampling algorithm) with the parameters of the information transmission device (throughput of the communication channel and the signal / noise ratio). The obtained attitudes can be used for designing the test station and optimizing it according to the cost criterion.

Keywords: test station, information, sensor.

\section{References}

1. Karpenko D.V. Stan ta perspektyvy rozvytku zenitnogho raketnogho ozbrojennja Povitrjanykh Syl Zbrojnykh Syl Ukrajiny: Naukovyj zhurnal "Nauka i tekhnika Povitrjanykh Syl Zbrojnykh Syl Ukrajiny”. 2017. №2(27). S.75-78. 2. Pribyljev Ju.B., Sakovych L.V. Pidkhid do pobudovy unifikovanoji universaljnoji avtomatyzovanoji kontroljnovyprobuvaljnoji stanciji raketnogho ozbrojennja: Naukovoteoretychnyj ta naukovo-praktychnyj zhurnal "Nauka i oborona”. Kyjiv. 2017. №1. S. 42-48. 3. Arkhangheljskyj Y.Y. Proektyrovanye zenytnыkh upravljaemskh raket. / Y. Y. Arkhangheljskyj P. P.
Afanasj'ev, Y. S. Gholubev, V. Gh. Svetlov y dr. M.:MAY, 2001. - 732 s. 4. Ghryb D. A. Udoskonalennja metodiv tekhnichnoji ekspluataciji i remontu jak osnova pidtrymannja bojeghotovogho stanu zenitnogho raketnogho ozbrojennja v suchasnykh umovakh [Tekst] / D. A. Ghryb, B. M. Lanecjkyj, V. V. Luk'janchuk // Nauka i oborona. 2012. - №3. - S. 55-63. 5. Permjakov O. Ju. Modelj systemy diaghnostuvannja, tekhnichnogho obslughovuvannja ta remontu skladnykh tekhnichnykh system vijsjkovogho pryznachennja. / O. Ju. Permjakov, Ju. B. Pribyljev, O. O. Djubanov. // Nauka i oborona. - 2016. №2. - S. 48-52. 